\title{
Making a Building Smart with a Co-Created and Continuously Evolving Enjoyable Service Entity-Insights from a Collaborative Study
}

\author{
Maaria Nuutinen ${ }^{1}$ **(D), Eija Kaasinen ${ }^{1}$, Jaana Hyvärinen ${ }^{2}$, Airi Mölsä ${ }^{2}$ and Sanni Siltanen ${ }^{2}$ \\ 1 VTT Technical Research Centre of Finland Ltd., FI-02044 Espoo, Finland; eija.kaasinen@vtt.fi \\ 2 KONE Corporation, FI-02150 Espoo, Finland; jaana.hyvarinen@kone.com (J.H.); airi.molsa@kone.com (A.M.); \\ sanni.siltanen@kone.com (S.S.) \\ * Correspondence: maaria.nuutinen@vtt.fi
}

check for updates

Citation: Nuutinen, M.; Kaasinen, E.; Hyvärinen, J.; Mölsä, A.; Siltanen, S. Making a Building Smart with a Co-Created and Continuously Evolving Enjoyable Service Entity-Insights from a Collaborative Study. Smart Cities 2022, 5, 1-21. https://doi.org/10.3390/

smartcities5010001

Academic Editors: Bin Jiang and Pierluigi Siano

Received: 31 October 2021

Accepted: 22 December 2021

Published: 24 December 2021

Publisher's Note: MDPI stays neutral with regard to jurisdictional claims in published maps and institutional affiliations.

Copyright: (c) 2021 by the authors Licensee MDPI, Basel, Switzerland. This article is an open access article distributed under the terms and conditions of the Creative Commons Attribution (CC BY) license (https:/ / creativecommons.org/licenses/by/ $4.0 /)$.

\begin{abstract}
Buildings shape cities as those cities grow from and nurture people living and working within the built environment. Thus, the conceptualization of smart building should be brought closer to the smart city initiatives that particularly target ensuring and enhancing the sustainability and quality of urban life. In this paper, we propose that a smart building should be interlinked with a smart city surrounding it; it should provide good experiences to its various occupants and it should be in an ongoing state of evolving as an ecosystem, wherein different stakeholders can join to co-produce, co-provide and co-consume services. Smart buildings require a versatile set of smart services based on digital solutions, solutions in the built environment and human activities. We conducted a multiphase collaborative study on new service opportunities guided by a Design Thinking approach. The approach brought people, technology, and business perspectives together and resulted in key service opportunities that have the potential to make the buildings smart and provide enjoyable experience to the occupants who support their living and working activities in smart cities. This paper provides the resulting practical implications as well as proposes future avenues for research.
\end{abstract}

Keywords: smart building; ecosystem; services; user experience; trends

\section{Introduction}

Buildings shape cities as those cities grow from and nurture people living and working within the built environment they provide. The development of the built environment framing and impacting our lives is an emotionally laden issue that raises contradictory perspectives in public as well as scientific discussions stretching over many disciplines. The drivers for design can be drawn from aesthetics, functionality, cultural values, and environmental issues but also from new technologies. The tension between technology driven and humane perspectives tend to remain although the tension is also catalyzing discourse forward [1-5]. Similarly to other attributes attached to buildings and the built environments the technology enabled "smartness" is a matter of definitions and degree [6]; the perspective we take, affects the interpretations and conclusions we would have. This paper aims particularly to contribute in advancing conceptualization of a smart building by bringing together human, technological and business perspectives. The guiding research question for the entire paper is: How can a building be made smart? We will provide a tentative definition of a smart building as a starting point. Then we will explore its dimensions with the help of a collaborative study focused on defining technology enabled occupant centric services that would provide business opportunities for the actors within a smart building ecosystem. The findings reflect the expectations of different smart building stakeholders and give insight of the opportunities of a continuously evolving set of services that will make future buildings smart. 
Digitalization is already profoundly changing the way we live and work. 5G networks, smart sensors and the Internet of things facilitate monitoring the environment and gathering data. Data from different sources can be integrated and analyzed with artificial, intelligencebased solutions to monitor the status of the environment and to predict how the status will change in the future. Digital twin technology allows the integration of gathered data with the physical environment, providing views on the history, present and future of the environment. Virtual reality technologies facilitate presenting digital twin data in connection with the 3D models of the environment. Augmented reality facilitates easy access to contextually relevant data in different locations. People in the environment can be identified with various technical solutions and this facilitates responding to their personal needs and preferences.

These kinds of new "smart" elements in our environment aren't inherently either good or bad, but their possibilities should be carefully considered. The smart elements can help tackle the serious challenges related to cities and buildings caused by e.g., climate change (extreme weather conditions), resource scarcity, security issues and a lack of physical and psychological safety and cybersecurity. Cities are important entities for business as they are estimated to contribute about $60 \%$ of global GDP and generate $80 \%$ of all economic growth [7]. Meanwhile, they also produce about $70-75 \%$ of all greenhouse gas emissions [8]. The construction industry and the buildings themselves, their materials, heating, ventilations etc. and other activities related to their use exploit scarce resources (e.g., water) and provide a significant amount of the global load of greenhouse gas emissions [8-10]. Technological development offers an important means for increasing the flexibility and the resilience of the built environment, for helping to prevent or mitigate the unwanted consequences of urbanization as well as for meeting quality of life and sustainability requirements (see e.g., $[3,4,11]$ ). For example, installing contemporary building automation can already result in significant energy savings at the building level, but connecting several buildings together within districts and with city level infrastructure paves the way for more advanced optimization let alone innovations. If people can be brought into this system as active agents with built environment embedded smartness, even more possibilities for progress can arise.

Furthermore, the smart elements can provide new ways to enhance joy, happiness, and the communality of people. Similar to the motivation of evaluating the quality of the built environment objectively, we can pursue a better understanding of how the "smartness" of a building can trigger these positive feelings. Based on the groundbreaking work of Christopher Alexander, the quality of the built environment or artifacts can be judged objectively as a living structure [12]. Alexander has showed how a city has a complex structure of overlaps, redundancies, ambiguity, and interactive relationships that allows combining sub-units similar to words of a sentence to form coherent wholes through design [13]. Under the notion of living structure even a mathematical model has been developed to characterize the degree of livingness or structural beauty and the verification findings further supporting the notion that goodness of things or images is largely a matter of fact rather than an opinion or personal preference as commonly conceived [14].

Additionally, smart city discussions and various smart city definitions include economic development, citizen well-being, sustainability and ICT enabled enhancement of service level, and these all together improve the quality of urban life [11,15]. We need innovative technical solutions to solve problems of urban centers in order to prevent negative impacts on the quality of life; smart city implementation can significantly support positive progress [11]. The smart city implementation driven by the public sector creates an important growing market for companies [16]. The global revenue forecast for smart city technologies, products, and services is $\$ 241$ billion in 2025 according to Statista [17]. The more private sector driven smart building market is also estimated to be in a clear growth curve regardless of the COVID-19 pandemic [18]: The global smart building market is expected to grow and the market for building automation is forecast to be 273 billion U.S. dollars by 2023 (based on Statista and McKinsey). These growing markets encourage 
companies to invest in new solution development and these investments are needed to advance smart city agendas. The act of bringing these still quite separate streams of smart city and smart buildings development closer to one another can benefit both initiatives and ensure that investments and research efforts create the maximum amount of impact.

Both smart cities and smart buildings serve the people in the buildings and in the city, making their lives easier in terms of economic, environmental, social, and cultural respects [19]. Like traditional buildings, smart buildings should trigger good feelings such as pride, belonging, healing, and well-being. As pointed out by Alexander [20], the built environment is always complete but still always evolving, constituting a living connection between the people and the place. In a smart building, the constantly evolving set of available services supports this living connection between the building and the occupants, i.e., people who work, live, or act the building as well as those who visit it. Smart buildings can form a core for flourishing service ecosystems referring to the dynamic, co-evolving, multilevel self-organizing networks of actors that have interdependency [21-23].

There are many definitions of smart buildings, but these definitions are often technology driven and vary internationally. We are highlighting technology as an enabler for people to be smarter and enhance the built environment to serve different aims of people living in cities (cf. [1]) but we want to pursue smart buildings towards being good spaces "in which or with people have good feelings, in terms of belonging, healing or well-being" referring to psychological and emotional comfort even feeling "their own existence in space" [2] (p. 1). In this paper, we define smart building as beginning from adaptability that is central to the definition by Buckman et al. [24]: Smart building adapts to different occupants' needs, supporting the activities of the occupant and providing positive experiences such as joy, happiness and communality. Smart building is a continuously evolving, integral part of smart city. Under this definition a smart building has the following dimensions:

(A) its role as a part of the bigger adaptive, resilient system of a smart city.

(B) its capability to provide joy, happiness and good experiences based on its responsiveness and adaptivity to the various occupants' individual needs and preferences.

(C) its role as an always ready and always evolving service ecosystem, bringing different actors together to co-create and co-provide new services.

In this paper we want to contribute to the current technology driven discussion on smart buildings with a more occupant centric perspective. We think that smart buildings are not just about advanced technology, but are rather about how technology enabled services can help make buildings more sustainable, more people centric, ensure better occupant experience and optimize the utilization of buildings within the broader system of the built environment. Furthermore, we claim, that buildings do not become smart by introducing individual services but by way of wide service entities that respond to the various needs of different occupants.

What kinds of services would different occupants of smart buildings appreciate now and in the future? We studied this issue in a collaborative project that involved different smart building actors and stakeholders. The smart building actors were committed to sharing building data and using a platform-based technology that would link developers, and facilitate gathering and sharing of data while also providing services as a united service entity. The service entity that will include interlinked, embedded, and personalized services will benefit from the continuous interaction and data flows between smart buildings' infrastructure, the occupants, and other stakeholders throughout the building's life cycle.

During the project, we studied key smart building stakeholders and their needs. To focus on future possibilities, we extended the study to relevant trends that influence what the occupants may expect in the future and what may become available. The main results presented in this paper are nine themes of service opportunities based on relevant trends and stakeholder needs. The proposed services' complete physical space make the building smart and trigger good experiences. The services increase adaptivity of the built environment and create links between different parts of the whole system that can then evolve with people. We discuss the findings and how they influence the three above 
described smart building dimensions. As a practical contribution, we open avenues for service development based on the three recognized dimensions of smart buildings.

In the following, in Section 2 we first describe related research on experience-driven design and service ecosystems in the context of smart cities and smart buildings. We then describe our Design Thinking approach and related methods in Section 3. Section 4 is devoted to presenting our results: the key smart building stakeholders and their experience goals, key global trends influencing the development of smart buildings as well as the service opportunities that we recognized. In Section 5 we discuss the results and how they could be utilized related to the three dimensions of smart buildings.

\section{Related Research}

The research interest towards smart cities and smart buildings has increased particularly during the last decade. To get the overview, we looked for publications on Web of Science database with having smart city/cities or smart building/buildings (and excluding the overlaps) as a keyword. Based on that rough analysis, we noticed that during this time the number of publications on smart cities has increased from 100 to over 1000 publications per year but on smart buildings the increase is much more moderate reaching approximately 300 publications yearly. When analyzing the overlaps between the used other keywords, we noticed that the amount of commonly used keywords has also increased indicating that these tracks of research are overlapping (although not so often explicated) and could benefit from further explicating the linkage conceptually.

Enhancing the quality of citizens' life and sustainability of cities are in the core of smart city agendas which are increasingly trusting the integration of new technologies with open innovation approach [15]. However, still quite little is known how open innovation shapes the actual implementation of a smart city concept as well as the experience of smart city actors [15].

The smart city is enabled by physical, social, economic, and institutional infrastructures as well as strong citizen involvement $[15,25]$. The citizen point of view and communality is emphasized in smart city research (e.g., [15,25-29]). One could expect a similar viewpoint in smart building-related research, but most research in that field is focused on technical enablers and solutions while the viewpoint of the occupant is less present. Occupant comfort is a common aim in research and development, but it refers mainly to technical solutions that support managing an indoor climate. One of the rare recent studies explicitly bridging smart city and smart building related research is by Apanaviciene et al. [19], which summarizes that "both smart cities and smart buildings serve people inside the buildings and inside the city, providing them with more rational and personalized solutions, making their lives easier in terms of economic, environmental, social, and cultural aspects" (p. 4). The study further defines five criteria for the operating stage of smart buildings to evaluate the availability of smart solutions and how well they are integrated into the smart city entity. These criteria cover solutions related to data, energy, mobility, environment and life (ibid).

Particularly when considering office buildings, building users can be defined as people who come into the building daily and carry out more or less the same types of activities while they are there [30]. Their roles include, e.g., office workers, technical, support, maintenance, and administrative work. In addition, visitors can be seen as building users. In addition to individual users, the users can be seen as user "units": individual users, teams, and organizations [30]. As noted before, we prefer to use the term "occupant" to refer to different people who work, live, or act or visit it, rather than those who just "use" it.

In many cases, the design of smart environments tends to focus on efficient performance [31]. However, experiential product qualities are important as users' identification with products influence users' attachment to and willingness to use them [32]. Further, sometimes adding "smartness" to technology increases complexity and need for monitoring, which is ultimately carried out by humans [33]. 
In a smart building ecosystem various stakeholders both experience the building with all it's services and influence other stakeholders' experiences. Both technical solutions and human activities shape the occupant experience. People live and work in smart buildings, so the focus should be on the holistic experience, rather than seeing occupants merely as users of the building. Within the life of occupants, their experiences are not restricted by the walls of a building but instead reach beyond the boundaries of the city, their previous experiences and their dreams and fears of the future. What provokes good experiences within a smart building is impacted by how the building "allows" them to live a meaningful and easy urban life within a smart city.

Technology needs to studied in the actual context of use, and the focus should be extended to the impact of technology on wellbeing [34]. It is important to study the subjective meanings that people give to their smart environments and what makes people feel attached to the environments [35]. In addition to focusing on single users, the social dynamics in user communities should be studied, focusing on social value and communal experiences [36]. The social value of the building is affected not only by the physical design but also by the design processes, organizational set-ups, building management, and the experiences of the occupants [36]. Xu [37] points out how experience is shaped by the lifecycle of the product and all of the touch points where users interact with the product or related services. New kind of collaboration over the traditional boundaries of the industries has been called for to ensure innovativeness and renewal. The emergence of novelty required for innovativeness is driven by a multiplicity of the cultural norms and meanings, and practices guiding and constraining individuals and organizations as institutions [38,39]. Putting together, enabling holistic good experience with smartness of built environments requires a broad and evolving network of different service providers and other actors from different industries that can together bring smoothness to the course of a day for occupants and communities. This kind of network can be approached as a business ecosystem. Business ecosystems are defined as networked, interdependent, and co-evolving business and innovation activities crossing the traditional boundaries of the industries $[40,41]$. The members of the ecosystem have a formal or an informal agreement about shared purpose and operation modes [41]. Ketonen-Oksi and Valkokari [42] propose that active participation of actors in value creation in ecosystems is enabled by (1) A clear vision and a shared value base on which the ecosystem activities can be built and (2) Facilitation to support the ecosystem actors to make new connections and to share their knowledge and resources in the interest of mutual benefit.

Service ecosystems approach to business ecosystems try to capture the essential role of value co-creation between the different actors. Service ecosystems are defined as complex, relatively self-adjusting systems of resource-integrating actors that are connected by shared institutional logic and provide mutual value creation through service exchange $[43,44]$. Referring to the seminal works of Vargo et al. [45], Vargo and Lusch [44], Akaka et al. [46] and Lusch et al. [47], Gölgeci et al. [48] summarize in their recent review the distinguishing characteristics of the service ecosystem approach: "the role of users as crucial actors of value co-creation"; "a unique focus on customer value creation and the co-evolving system of interdependent actors and their actions"; and capability of the service ecosystem to "create value for all actors by appropriate resource integration" (p. 1-2) The service ecosystem of a smart building can thus include the different occupants, their networks and even service providers of broader city if and when they can bring value through better integration of different resources. The role of experience is essential here since actors are "cocreating value through holistic, meaning-laden experiences" [44] (p. 7), and value is "uniquely and phenomenologically determined by the beneficiary" [44] (p. 8).

In the ecosystems, physical and digital platforms serve as crucial tools for mutual value co-creation and collaboration [42,49-51]. Platform-based technology ecosystems are new forms of organizing independent actors' innovations [52]. This collective organization is providing superior-to-traditional, vertically integrated systems in many sectors because of the ecosystem's capacity to foster complementary innovation from autonomous, hetero- 
geneous firms, which extends the usage scope and value of the platform to the users [52]. Platform-based ecosystems will give companies new opportunities by changing how they interact with each other, often also disrupting the traditional business rules. In this sense, platform economy facilitates a marketplace where different service providers have business possibilities and can together create pleasant experiences to the users of the building. Smart buildings can provide 'a hybrid platform' where digital and physical dimensions meet [53] thus offering a unique opportunity to benefit from both dimensions. Since the built environment creates an arena for human mental and social activities, the important elements of space design and human activities (physical, digital or virtual, mental and social) are brought together $[34,36,54]$

While user requirements have received some focus within construction and architectural research, empirical investigations into how end-user needs can be gauged during project execution remains a largely an unexplored area [55]. Building users' behavior is influenced not just by the space they occupy but also by their feelings, intentions, attitudes, and expectations as well as by the social context in which they are participating. Studying user experience in a building offers understanding not only of how behavior is influenced by the environment, but also of how users act in their environment and how such behavior redefines the user-building relationship [30]. The theories of the built environment that approach users' experiences of built space are important in that they provide a lens to view the creation and management of the built environment to serve the sole purpose of supporting the needs of its end-users [55]. Deeper understanding of building occupants activities can help building designers, engineers, and managers to better understand how occupants respond to the spaces they occupy [56].

\section{Methods}

This study was carried out in a project that includes both research and industrial partners. The industrial partners include companies who provide different technical solutions for smart buildings. The companies include a construction company, an elevator and escalator manufacturer, an air conditioning manufacturer, two ICT solution providers specialized in building performance and cybersecurity as well as a company providing wireless connectivity solutions. The participating companies represent different viewpoints in the smart building ecosystem. The project has a common vision: "Making every building smart". According to the vision, future buildings will be smart and connected during the entire lifecycles of the buildings. The buildings will be predictive and responsive, and for the occupants, the buildings will offer new kinds of personal experiences. To realize the vision, different smart building actors should share data and have a common platform from where the data-driven services can be provided. The project partners and external actors plan to form an ecosystem to connect stakeholders and to digitalize buildings with networks of sensors, devices, and services. Following the idea of the platform economy facilitating a marketplace where different service providers could have business possibilities and together create pleasant experiences for the occupants of the building, a development platform was targeted. The aim of the project is to study how to build this kind of a smart building ecosystem, and what kinds of services in smart buildings will provide value to the occupants.

We have been using "Design Thinking" [57], as the design methodology in our project. According to Lockwood [58], "Design thinking is essentially a human-centered innovation process that emphasizes observation, collaboration, fast learning, visualization of ideas, rapid concept prototyping and concurrent business analysis, which ultimately influences innovation and business strategy". Design thinking aims to integrate in the creative design process the viewpoints of human users (desirability), technology (feasibility) and business (viability).

Due to its design thinking methodology approach, the project has included various interactive, engaging, and empathetic activities where all project partners have participated. Our aim has been to facilitate direct contacts between project partners and the building 
stakeholders throughout the design process. We believe that by empathizing with occupants and other stakeholders, the project team members will gain insight into the building ecosystem, and this supports the development of better solutions.

Design thinking process is typically organized into five phases: empathize, define, ideate, prototype and test. In the study described in this paper, we focus on the early design thinking phases: empathize (data collection to gain user understanding), define (data synthesis to gain a refined understanding of user needs) and ideate (based on the results of the earlier phases, challenging assumptions and co-creating ideas). The design thinking process is illustrated in Figure 1 and Table 1 describes further details of the different methods that were used.
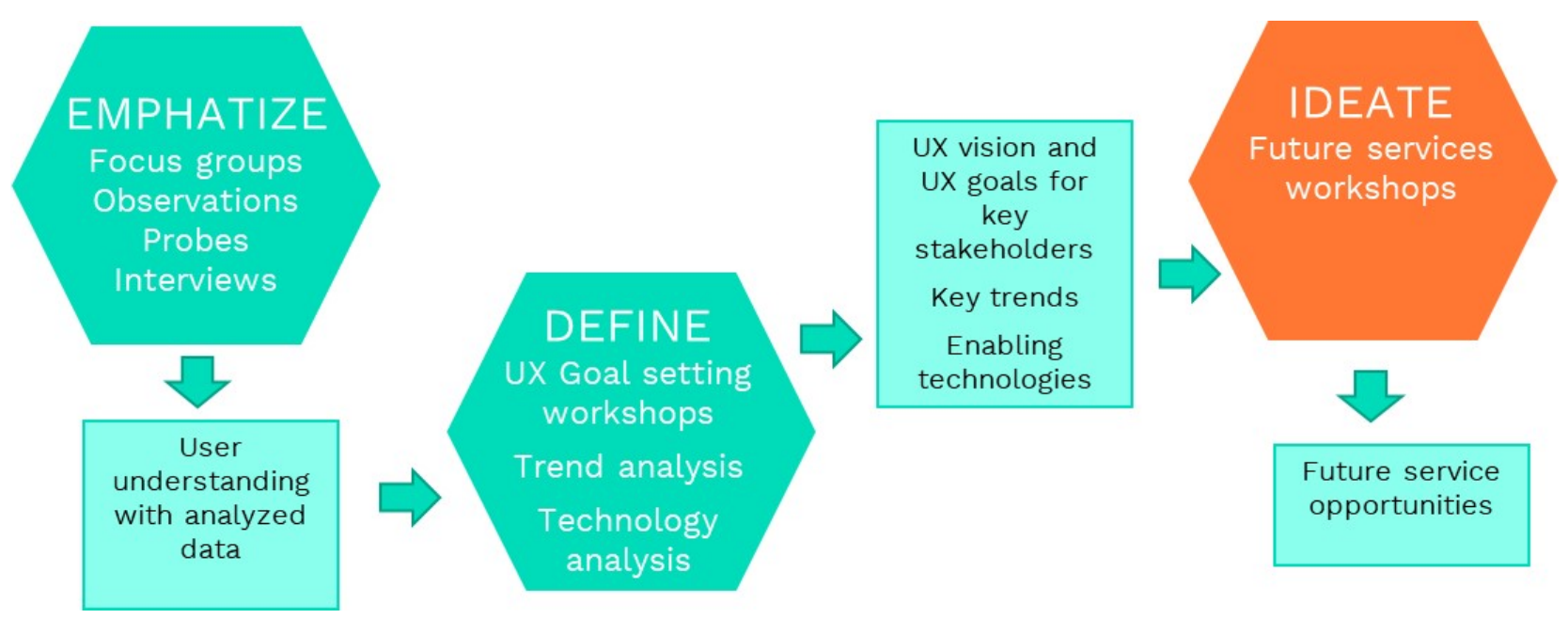

Figure 1. The design thinking process phases and their results.

Table 1. DT process methods, participants and aims.

\begin{tabular}{|c|c|c|c|c|c|}
\hline DT Phase & Method & Participants & $\mathbf{N}$ & f2f/Online & Aim \\
\hline \multicolumn{6}{|l|}{ EMPATHIZE } \\
\hline & Focus group 1 & $\begin{array}{c}\text { Project group + } \\
\text { stakeholders, Building } 1\end{array}$ & $13+20$ & $\mathrm{f} 2 \mathrm{f}$ & To identify stakeholder needs \\
\hline & Focus group 2 & $\begin{array}{c}\text { Project group }+ \\
\text { stakeholders, Building } 2\end{array}$ & $26+20$ & online & To identify stakeholder needs \\
\hline & Probes & $\begin{array}{l}\text { Stakeholders of the two } \\
\text { case buildings }\end{array}$ & 18 & $\mathrm{~N} / \mathrm{A}$ & $\begin{array}{l}\text { To empathize with stakeholders' } \\
\text { daily life }\end{array}$ \\
\hline & Interviews & $\begin{array}{l}\text { Stakeholders of the two } \\
\text { case buildings }\end{array}$ & 25 & f2f\&online & $\begin{array}{l}\text { Deeper understanding of } \\
\text { stakeholders' daily life }\end{array}$ \\
\hline \multicolumn{6}{|l|}{ DEFINE } \\
\hline & $\begin{array}{l}\text { UX Goal setting } \\
\text { workshop } 1\end{array}$ & Project partners & 38 & online & To define initial UX Goals \\
\hline & $\begin{array}{l}\text { UX Goal setting } \\
\text { Howspace }\end{array}$ & Project partners & 10 & online & $\begin{array}{l}\text { To discuss and refine the } \\
\text { UX Goals }\end{array}$ \\
\hline & Trend workshop 1 & Project partners & 11 & online & $\begin{array}{c}\text { To identify and discuss } \\
\text { relevant trends }\end{array}$ \\
\hline & Trend workshop 2 & Project partners & 12 & online & To prioritize the trends \\
\hline
\end{tabular}


Table 1. Cont.

\begin{tabular}{cccccc}
\hline DT Phase & Method & Participants & N & f2f/Online & Aim \\
\hline IDEATE & & Researchers & 8 & online & $\begin{array}{c}\text { To practice the } \\
\text { workshop method }\end{array}$ \\
\hline $\begin{array}{c}\text { New services } \\
\text { workshop 1 } \\
\text { workshop 2 }\end{array}$ & Project partners & 15 & online & $\begin{array}{c}\text { To ideate new services, put } \\
\text { them to timeline and prioritize }\end{array}$ \\
\hline $\begin{array}{c}\text { New services } \\
\text { workshop 3 }\end{array}$ & $\begin{array}{c}\text { Project partners + service } \\
\text { developers } \\
\text { New services } \\
\text { workshop 4 }\end{array}$ & Researchers & 86 & online & $\begin{array}{c}\text { To ideate further services, put } \\
\text { them to timeline and prioritize }\end{array}$ \\
\hline
\end{tabular}

During the empathize phase, we were using four kinds of data collection methods: stakeholder workshops, observations, design probes [59] and interviews. To get an overview of the different stakeholders and their needs, we studied two existing different building ecosystems in detail. These ecosystems were business buildings that, in addition to the companies, also hosted different service providers. We started with two building ecosystem specific focus group meetings to identify key stakeholder groups and how they are connected. The focus group participants were project partners as well as stakeholders of the buildings. The project group represented the different companies and the research organization collaborating in the project, and the individual project members represented the three viewpoints of the project: business, technology and user experience. Building 1 was a newly renovated business campus that hosted startup companies. The focus group participants included representatives of those startups as well as business campus staff. Building 2 was in the planning phase. The focus group participants included members of the design and construction team as well as representatives of the company that was going to be the main tenant of the building. In the latter the main focus was on facility management. In the workshops, the participants were working in groups that were each focusing on a certain building life cycle phase. The role of the project members was to ask questions from the building stakeholders and thus try to identify key building stakeholders and their connections. The groups were using Lego characters to describe key stakeholders and connections between them. Based on the focus groups, Building 1 stakeholders were complemented with further tenant company representatives, further members of the business campus staff as well as external service providers. Building 2 stakeholders were complemented with further design group members as well as further representatives of the main tenant company, especially reception staff and facility management staff.

After the focus group results were analyzed, we organized interviews with relevant stakeholders. The interviewees included people who had already participated in the focus groups and representatives of stakeholder groups that had been identified in the workshops. Additionally, within the interviews we identified some additional stakeholder groups and added new interviewees accordingly. In the interviews our aim was to identify stakeholder needs and their relationship with the other stakeholders. Probes were utilized in the form of two week probes, where the building stakeholders wrote down their daily activities in a semi-structured diary. The interviewees were asked whether they would like to keep the diary, and some of the interviewees agreed to do so. With those stakeholders who participated in the probes, the diaries were used as background material in the interviews. The diaries helped in identifying key activities and the stakeholders participating in those. With those interviewees who did not participate in the probe, the interviewer was asking about activities during their past work week to identify key activities and related stakeholders. Our aim was to identify the different stakeholders' needs but also to gain a more holistic view into it by considering the whole building ecosystem and social dynamics within it. The data collection methods were interconnected: each method provided insight for the 
subsequent step (e.g., design probes prepared the interviewer and the interviewee for the interview session). After the data gathering activities were completed, the data was put together and analyzed.

In the define phase, we were utilizing the user experience (UX) goal setting approach [60] to combine understanding the occupant with technology promises and business possibilities to define UX goals and further, UX vision. The results of the empathize phase were analyzed in a workshop, and UX goals for key occupants were defined accordingly in small groups, each focusing on a certain building life cycle phase. Once the UX goals were defined, they were presented in an online collaboration tool (Howspace) and project partners and other stakeholders were invited to discuss and comment on the UX goals. This online discussion lasted for two weeks. The UX goals were refined accordingly. The UX goals and the UX vision communicate the identified occupant needs to the next phases of the design thinking process.

In the define phase we also studied global trends that may influence smart buildings in the future. We started with four megatrends: aging and diverse population, sustainability and ecological reconstruction, urbanization as well as digitalization. For the trend workshop, we invited 1-2 participants from each project partner organization based on their interest in foresight studies. Before the workshop, the participants were asked to study relevant trends and prepare the introduction of 4-5 trends that they felt were important. In two successive workshops, the trends were presented, clustered to relevant themes and prioritized. The outcome was 10 key trends that the project group considered to be the most influential in the smart building context.

Finally, in the ideate phase, we were using the UX visions and UX Goals, the identified trends as well as key technical enablers as the basis for ideating future service possibilities. We also described and illustrated various contexts of use and events to inspire ideation. These materials were shared with project partners in two successive workshops, where the participants suggested service ideas based on the materials. The ideas were first generated individually, then discussed and thematized in a group, and finally each participant could vote for the best ideas. To stretch the participants' imagination in the workshops, we applied a mental time travelling [61], technique for facilitating imagining and feeling aspects of the future, on a level of detail that would be difficult to produce otherwise.

The design thinking definition and ideation phases took place during the Covid-19 pandemic. Given that in-person workshops were no longer possible, we organized online workshops. Online meeting software (MS Teams) was used to facilitate audio and video connections. The Howspace tool was used as an online collaboration tool during the UX goal setting. The Miro online whiteboard was used to co-create and discuss ideas during the ideation phase. A partial view of a Miro Board resulting from an ideation workshop is illustrated in Figure 2. The whiteboard, with which each group was working included several similar idea groups. 


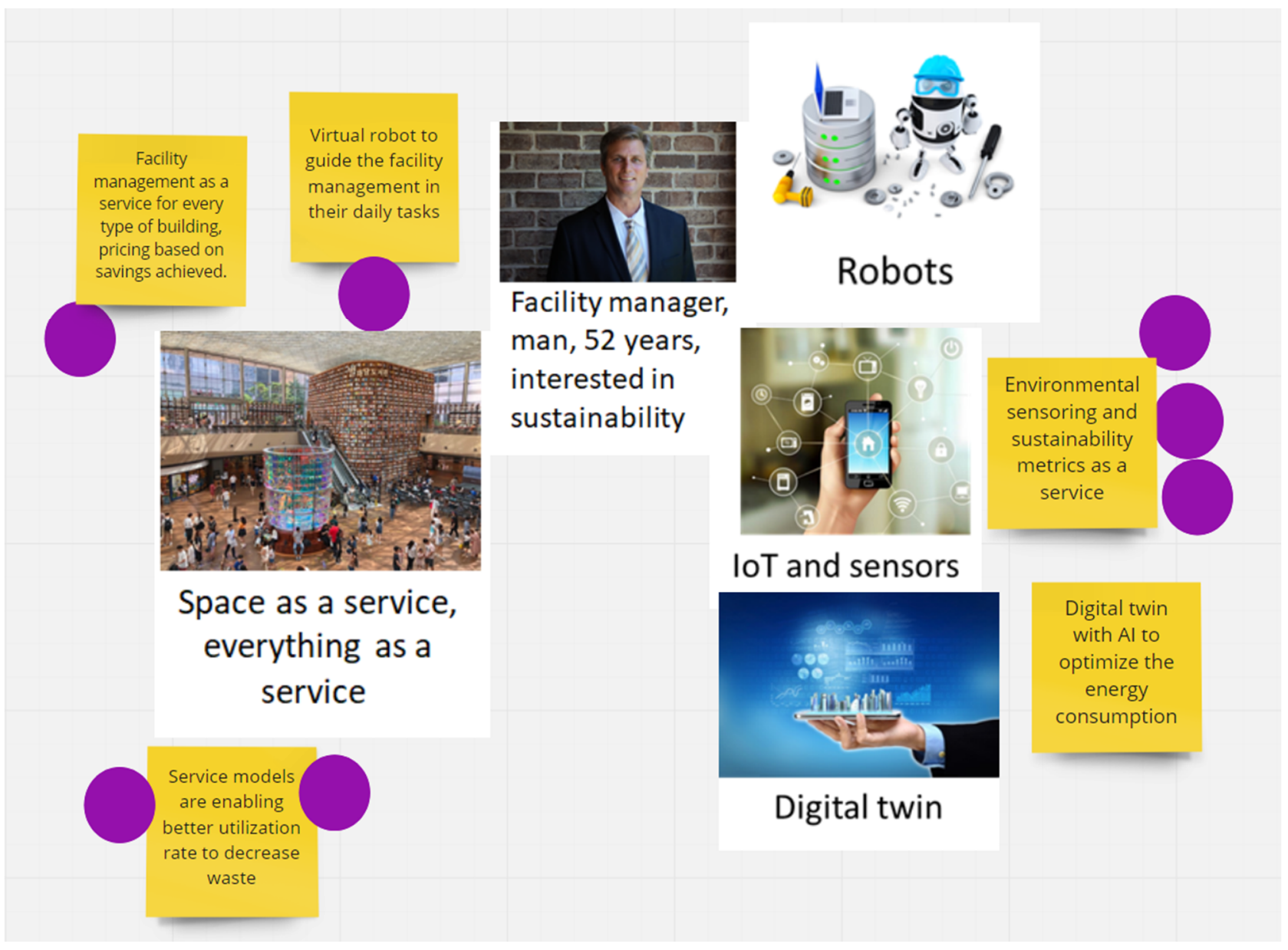

Figure 2. Example of the thematized ideation results and votes in Miro online Whiteboard (partial view of the whiteboard).

\section{Results}

The results of the early phases of the design thinking process included an overview of key smart building occupants, UX vison and UX goals for key occupant groups, key trends that will influence smart buildings as well as prioritized service ideas. In the following sub sections, we describe these results.

\subsection{Key Smart Building Occupants and Their Experience Goals}

The studied buildings had various occupants. Some occupants mainly used the buildings as their work environment while others were responsible for operating and maintaining the building or providing services to other occupants. In addition to the permanent occupants, there were also visitors and external service providers visiting the building occasionally or on a more regular basis. The occupants were interacting and collaborating in various ways. As an example, Figure 3 illustrates the different stakeholders, with which the company tenants have a business relationship. Herein, the term tenant refers to permanent occupants of the building who work at one of the tenant companies. 


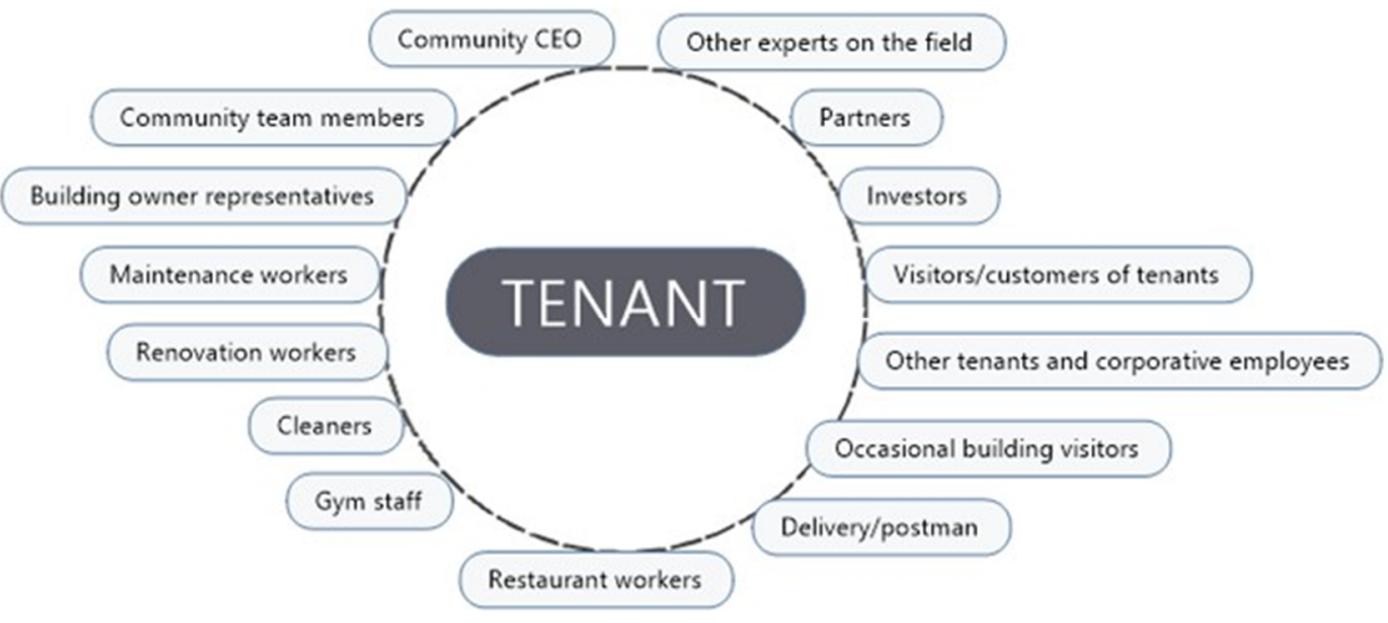

Figure 3. Key stakeholders at one of the studied buildings from the tenant's point of view [62].

During the empathize phase we gradually refined our understanding of the key occupant groups and their needs. In smart building operation, key occupants are people responsible for facility management and external service providers. Key occupants in using smart buildings include tenants and visitors. The gathered understanding of these occupants was interpreted into UX goals for key occupant groups. The UX goals were crystallized as a UX vision for each key occupant group, reflecting the overall targeted experience for the occupant, enabled by smart building solutions. The UX vision and the related UX goals communicate the experiences that smart building solutions should evoke with different occupants. Figure 4 illustrates the UX visions for the key occupant groups: people responsible for facility management, external service providers, tenants and visitors.

\section{$\underbrace{10}_{0}$ \\ Facility management}

\author{
Being aware \\ to monitor, \\ plan and \\ communicate.
}

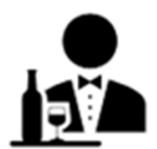

\section{External service provider

\author{
Feeling pleased \\ to be able \\ to serve well
}

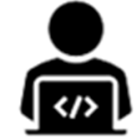

Tenant

$$
\begin{aligned}
& \text { Feeling cared for } \\
& \text { and empowered } \\
& \text { as part of the } \\
& \text { community. }
\end{aligned}
$$

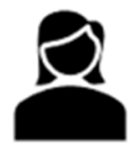

Visitor

Figure 4. The UX visions for key occupant groups.

People responsible for facility management need to ensure that the building and surroundings are clean, safe, and comfortable for all occupants. This requires monitoring the status and taking care of both scheduled and exceptional maintenance tasks. Facility management is also needed to prepare for the future by predicting occupant needs as well as future maintenance and renovation needs.

External service providers include actors providing e.g., cleaning, security, or catering services. These actors want to serve their customers well, and thus knowing and predicting customer needs is crucial. External service providers may need to work daily in several different buildings, so easy access and navigation support are important.

Tenants include people who use the building regularly, such as employees of the tenant companies. They appreciate a comfortable, healthy, and safe working environment, and possibilities to influence it as members of the community. 
Like external service providers, visitors need easy access and personal navigation and other support in the building to feel welcome and confident when entering and acting there.

The UX goals describe the expectations of the four key occupant groups in details, as illustrated in Figures 5-8.

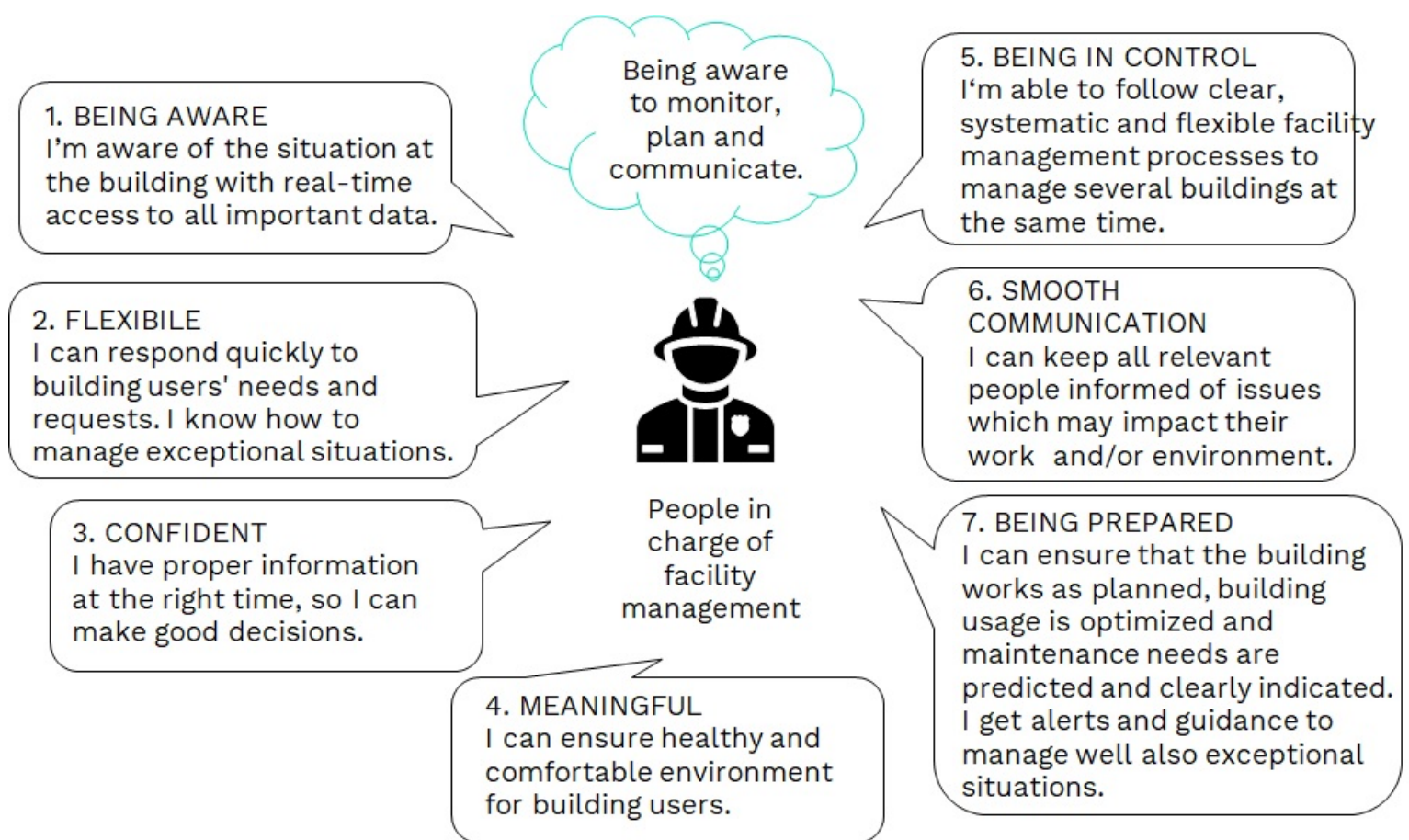

Figure 5. The UX vision and UX goals for people in charge of facility management.

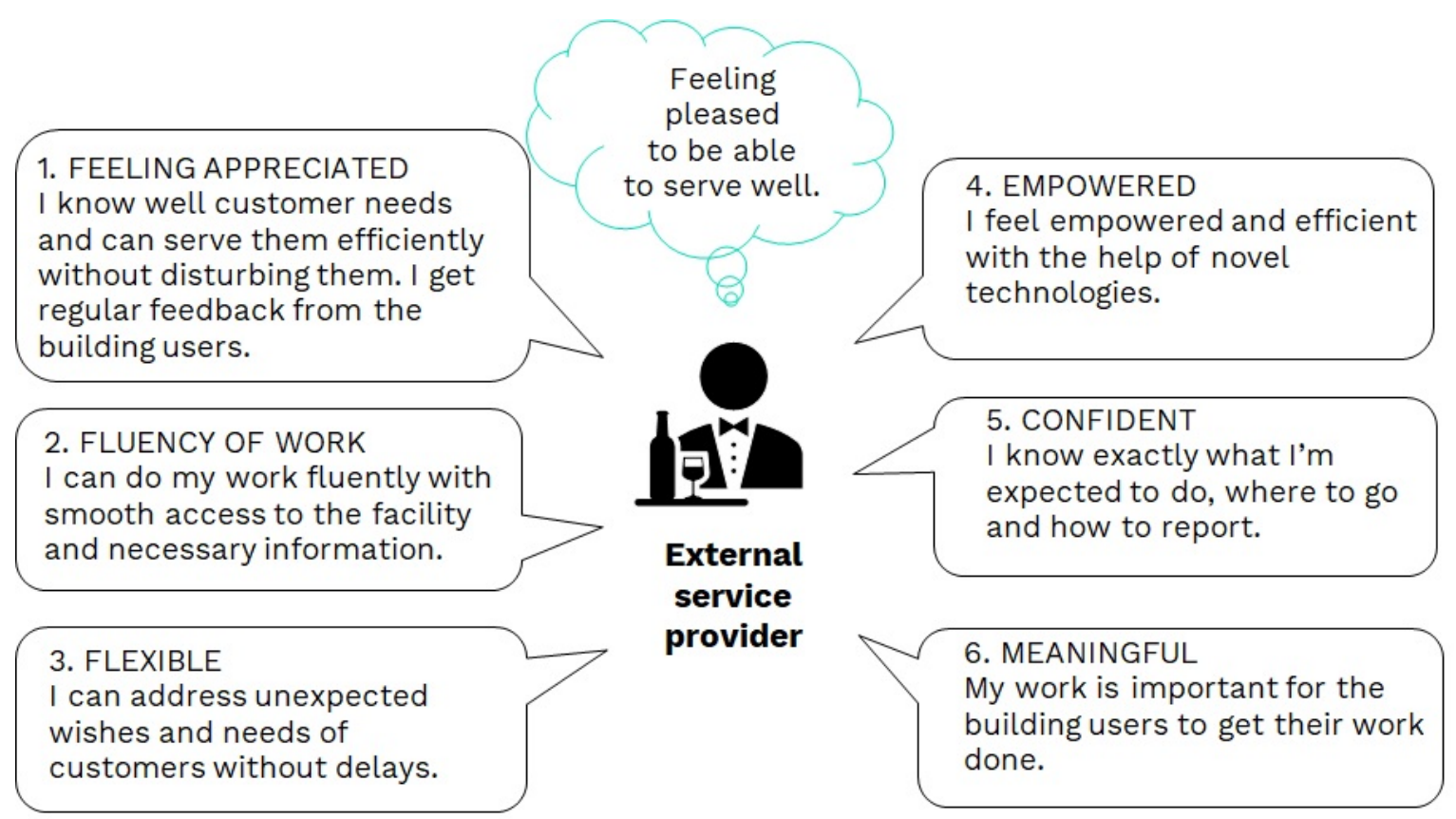

Figure 6. The UX vision and UX goals for external service providers. 


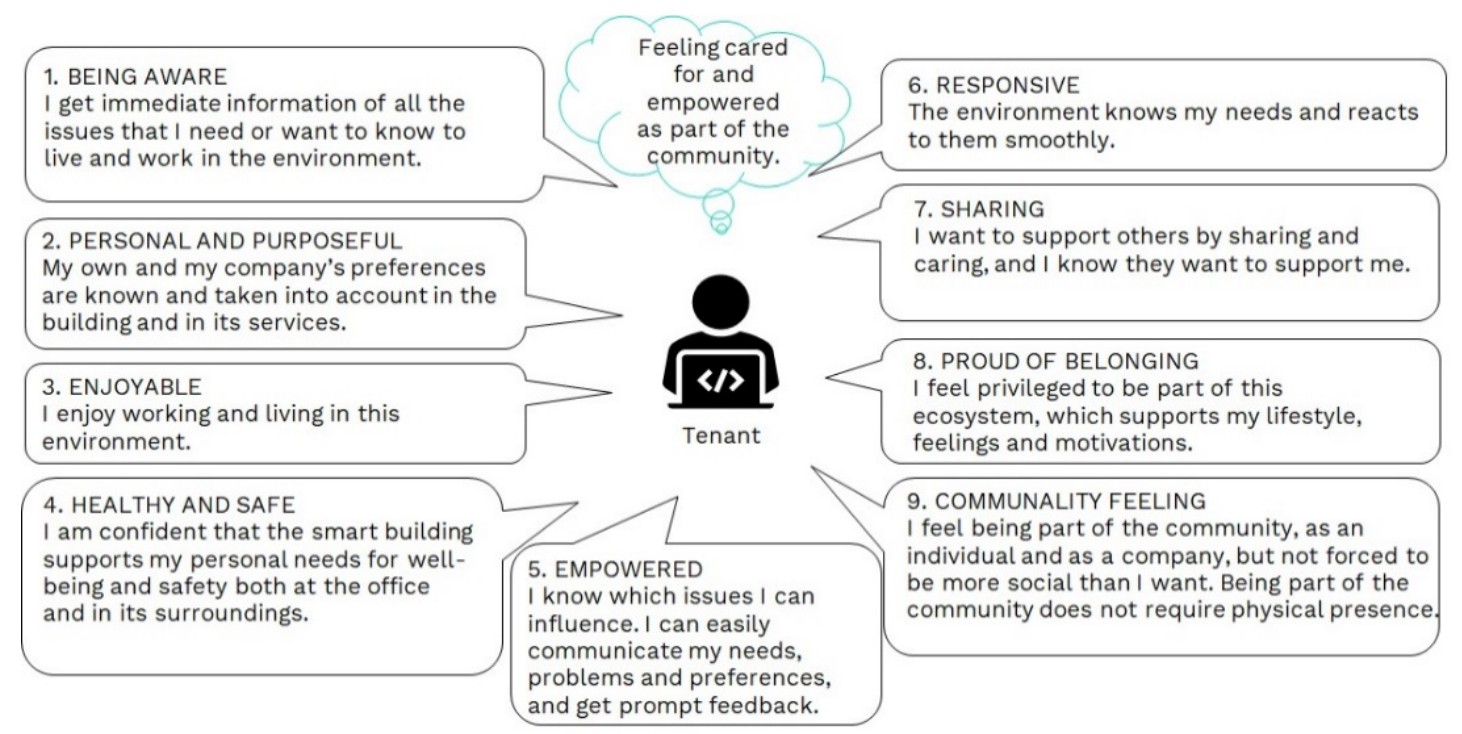

Figure 7. The UX vision and UX goals for tenants.

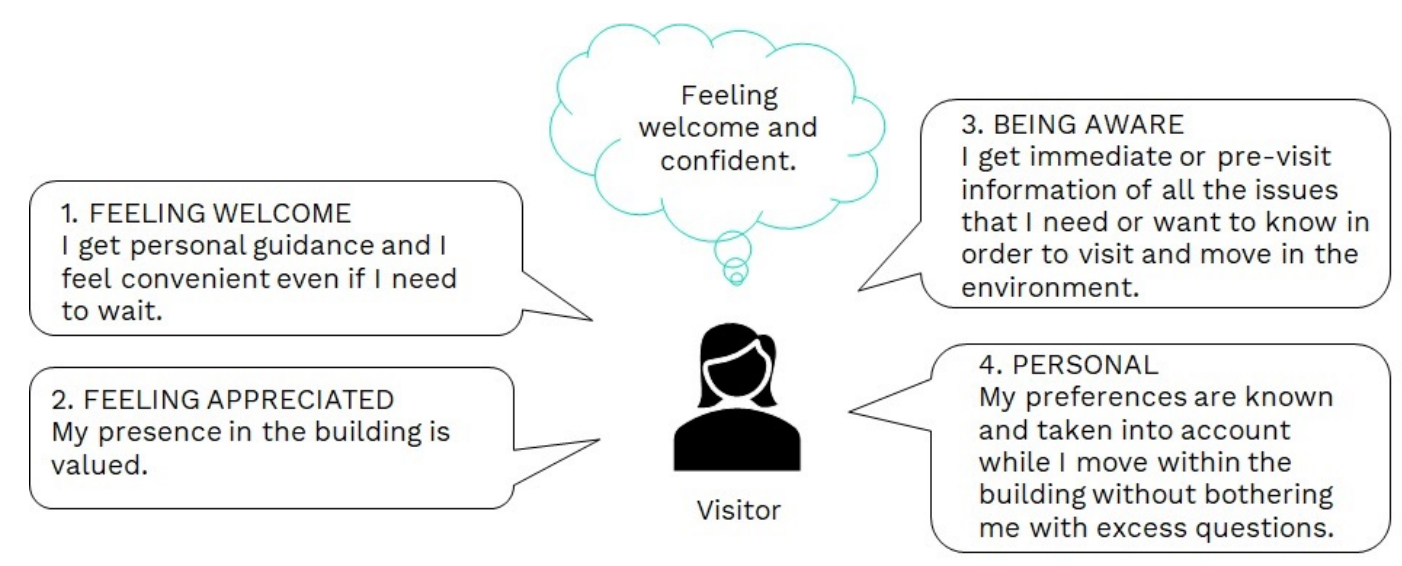

Figure 8. The UX vision and UX goals for visitors.

\subsection{Smart Building Related Trends}

During the definition phase, the project group agreed 10 key trends that are most strongly influence future smart buildings and related services. These trends are the following:

1. Digitalization overdose-new demand for human contact. The digitalization megatrend is changing the world so that almost everything can be done digitally. In the increasingly digital environment, people miss human contact.

2. Sustainability: energy efficiency and recycling demands. People are increasingly aware of climate change and how their consuming behavior influences the change. People are willing to change their behavior towards sustainable living.

3. Space as a service, everything as a service. Servitization is a major trend: people do not want to own consumables, but they want to buy usage as a service. This is also exhibited in how the built environment is used.

4. Individually tailored living and working environments. People have different capabilities and preferences and they want that them to be considered in the environment.

5. Post Covid demands for smart hygiene in buildings. The pandemic has created new hygiene demands and standards in built environments.

6. Hybrid work environments integrating office workers and remote workers. Remote work has expanded during the pandemic. While people are returning to offices, they still partially work remote. 
7. Need for modularity and upgradability. During the life cycle of a building, it's usage purposes may change many times, requiring flexible renovation.

8. Sharing economy. People want to utilize the equipment they own by sharing with others either by owning together or by renting to others.

9. Communality. People participate by developing areas and services in areas and can contribute to service offering.

10. Smart machines in human communities. Robots and other smart machines are a substantial part of the built environment.

\subsection{New Service Opportunities}

In the ideate phase, we identified the most promising service possibilities in connection to the chosen relevant trends. The individual service ideas were grouped to service opportunities related to the trends. The service opportunities cover all ten of the chosen trends but two (Space as a service, everything as a service and Need for modularity and upgradability) the service ideas were overlapping and thus they were combined into a single service opportunity. It is noteworthy that most of these service opportunities do not represent just digital services but implementing the services will also require changes in the built environment as well as changes in occupant practices. Even if most services can be provided digitally, many services also require human actors, or services can be improved by adding human-operated elements. In the following, we describe the resulting nine service opportunities. In Table 2, we give examples of how the proposed services would respond to the UX goals of the occupants.

Table 2. Examples of occupant UX goals, to which the proposed services could respond.

\begin{tabular}{ccccc}
\hline Service Opportunity & $\begin{array}{c}\text { Facility } \\
\text { Management }\end{array}$ & $\begin{array}{c}\text { External Service } \\
\text { Providers }\end{array}$ & Tenants & Visitors \\
\hline $\begin{array}{c}\text { Services available } \\
\text { for anyone }\end{array}$ & $\begin{array}{c}\text { Smooth } \\
\text { communication }\end{array}$ & Fluency of work & Being aware & Feeling appreciated \\
\hline $\begin{array}{c}\text { Sustainable choice is the } \\
\text { easiest choice }\end{array}$ & Being prepared & Fluency of work & Being aware & Being aware \\
\hline $\begin{array}{c}\text { Space at your service } \\
\text { Feeling confident and }\end{array}$ & Flexible & Flexible & Responsive & Feeling welcome \\
\hline $\begin{array}{c}\text { Supporting your health } \\
\text { Breaking limits of space } \\
\text { and distance }\end{array}$ & Meaningful & Confident & Personal and & Personal \\
\hline $\begin{array}{c}\text { Give power to the people } \\
\text { Responsible consuming }\end{array}$ & Flexible & Feeling appreciated & Proud of belonging & Feeling aware \\
\hline $\begin{array}{c}\text { Machines as members of } \\
\text { our community }\end{array}$ & Flexible & Meaningful & Sharing & Feeling welcome \\
\hline
\end{tabular}

Services available for anyone-connected without gadgets (Trend: Digitalization overdose-new demand for human touch). Smart building services should be easily available for both permanent occupants and occasional visitors without extra effort-regardless of their differences (related, e.g., to their demographic characteristics or capabilities). The building can support people in several ways regarding, e.g., comfort, safety and guidance with technology embedded in the building infrastructure. The provided infrastructure can also support robots providing services related, e.g., to indoor logistics. These services can be utilized without interaction devices or with interaction devices integrated into the environment.

Sustainable choice is the easiest choice-services support sharing and using resources intelligently (Trend: Sustainability-energy efficiency and recycling demands). Different 
services can support sharing and using resources smartly. Ecological, economic, and social sustainability requires efficient and fair use of all resources, whether energy, material, equipment, or infrastructure during the whole life cycle of the buildings. These services help people to make sustainable decisions and help others to do so too by monitoring, predicting, and guiding sustainable behavior and use of resources. Predictive functions can enhance, e.g., energy efficiency in the building. Occupants can get motivational feedback on the impact of their consumption choices.

Space at your service-supporting different usage possibilities (Trends: Space as a service-everything as a service and Need for modularity and upgradability). Smart building is designed to adapt for different usage possibilities and to provide related services. As the usage purpose and user group is changing, available services can be changed accordingly. Smart buildings can provide these possibilities through modularity and software-based upgradeability and adaptivity. This logic can be utilized for every phase of the lifecycle of the building. Access to spaces and other building resources can be provided as services. The same space can serve different user groups at different times, e.g., office space can change into a restaurant in the evening.

Feeling confident and relaxed everywhere-personalized services (Trend: Personalization-Individually tailored living and working environments). If the smart building knows about the characteristics and preferences of individual occupants, they can be served individually. This requires that the occupant can be identified in a secure and respectful manner and that the occupant can inform the smart building about his/her characteristics and preferences. The smart building can also automatically identify some characteristics and behavior, then gradually learn about preferences. Personalization needs to be easy and voluntary. The privacy of the occupants must be respected, and they must be aware and give permission if they are monitored in the space. To provide significant benefit, it should be possible to utilize the same user profile in different smart buildings. Then the occupant can get familiar services personalized according to his/her profile even when visiting a building the first time. Services can adapt to the personal needs and preferences of individuals, for example, knowing their health status and specific needs and providing personalized navigation and other guidance. Occupants can be provided with personalized indoor comfort regarding, e.g., temperature and lighting

Supporting your health-situationally adaptive services that enable the building to be kept clean and safe (Trend: Post Covid demands-smart hygiene in buildings). During the COVID-19 pandemic, awareness and requirements regarding hygiene have grown. Smart buildings can support the maintenance of hygiene by monitoring the environment and recognizing cleaning needs. The building can monitor and guide the occupants to support responsible behavior. Guiding and supporting healthy behavior must be done without embarrassing people. Health monitoring can be provided as a part of building infrastructure and sensor technology can be utilized to make sure air is clean and virus-free. Cleaning needs can be recognized by monitoring space usage, and robots can provide situationally adaptive services for cleaning when needed.

Breaking limits of space and distance-equal collaboration for remote and on-site occupants (Trend: Hybrid work environments-integrating office workers and remote workers). Smart building services can support smooth and effective communication and collaboration in the hybrid work teams as well as creating a socially active and fair hybrid work environment. On-site and remote employees should be provided with equal services and possibilities. Embedded digital elements create a sense of being present regardless of actual distance, hence enhancing organizational culture and brand building. All-embracing remote connections can support shared situational awareness of different actors during the whole lifecycle of the buildings providing benefits for multiple service providers. Virtual and augmented reality can be utilized to connect on-site and remote workers. Digital co-working platforms can be embedded in smart buildings.

Give power to the people-support local communities with services that help to influence (Trend: Communality-people participating in developing areas and services, 
and contributing to service offering). Local communities can be empowered by involving them into decision making on design and development of the building, the surroundings and service offering. The empowerment itself can support the creation of a community and benefit the innovation potential of people. Smart buildings can provide community spaces such as public cooking space or community gardens. Services can request timely feedback, making communication between different actors transparent and even automatic by collecting (authorized) personal data and preferences of local occupants. Digital models and VR/AR applications can provide attractive and collective participation platforms as early as the design phase of the building and further when developing the area.

Responsible consuming-sharing made easier and more tempting than owning (Trend: Sharing economy-From ownership to usership). Smart building includes a lot of spaces and equipment to be shared. The building can provide services that support sharing equipment and services locally. Smart buildings and advanced technologies provide excellent platforms for sharing resources and thus enabling stakeholders to utilize and experience different services without ownership. The benefits of shared services are, for example, the possibility to share economic costs, and on the other hand, earn by sharing one's own property with other users; the possibility to test various services without long commitment periods as well as the sustainability factor. A smart building can support sharing, e.g., office and other spaces; mobility equipment such as cars, bikes, and e-scooters; sports equipment and different seasonal equipment.

Machines as members of our community-smart machines serving people 24-7-365 (Trend: Smart machines in human communities-Extended service possibilities). Buildings already host different automations and smart machines. With robots and AI-based solutions, smart machines are increasingly present in the environment. E.g., a service robot can identify a potentially puzzled person, approach him/her and offer help. Smart buildings include lot of hidden intelligence, but there is real experience ahead of us in letting technology be visible and involved as a part of our living and working environments. Smart buildings can support smart machines in serving occupants in responsive, sensitive, communicative, and collaborative ways-any time, all year round.

Table 2 presents examples of how the proposed service opportunities can and should enable positive experiences of different occupants. As stated earlier, not only do the smart building solutions contribute to experiences in a building, but also other people do as well. For example, when developing a service for the building's visitors based on the services available for anyone-connected without gadgets opportunity, it should not jeopardize the good experience of concierge or reception personnel (provided by an external service provider). The business potentiality of a service can be expected to be higher if it benefits many occupants and other stakeholders rather than disturb their activities or business.

\section{Discussion}

Our findings give insight to the expectations and opportunities related to future smart buildings. The main results of this study were user experience goals in smart buildings for key occupant groups as well as service opportunities organized in nine themes based on relevant trends. The results can be utilized when designing smart building platforms and services. What has the study taught us regarding what is smart building, and how a smart building can be realized? In the beginning of this study, we defined three dimensions for a smart building. Our learnings are covering all these dimensions as discussed below:

(A) Smart building as a part of the bigger entity of a smart city.

Thus far smart city and smart building research seem to have followed quite different paths as pointed out by Apanavicience et al. [19]. While smart city research has been citizen centric, smart buildings have mostly been studied as contexts where one can introduce new technologies. However, as pointed out by Apanavicience et al. [19], both smart cities and smart buildings should serve people and make their lives easier. Even if the focus of our study was individual buildings, the stakeholders we studied represent citizens who live and act not only in the studied buildings but also in many other buildings in the city and its 
surroundings. Like the physical infrastructure in cities, the future digital infrastructure and services should constitute a coherent entity. This supports the notion of citizens gradually learning what kinds of services can be expected to be available at different spaces, and how the services can be accessed. For instance, the services that guide sustainable behavior would benefit if they can be extended from the individual building to other buildings and the surrounding city. Optimally, people can use the same smart building services at different buildings, and they can utilize the same user profiles with different services. Smart building services should be developed in connection to the local smart city context to support widespread adoption of the services.

(B) Smart buildings as a means of providing joy, happiness, and good experiences to different occupants and other stakeholders.

Current research on smart buildings is quite focused on technical enablers. The research focus should be extended to how users act in their environment $[30,56]$, the subjective meaning the users assign to their environment [35], social dynamics between users [36] and people's needs within urban and social domains [3]. Our design thinking approach with UX goal setting for different stakeholders has aimed to tackle these challenges. In our study, service opportunities were recognized based on relevant trends and occupant experience visions. We believe that this kind of approach has brought out more promising possibilities than the mere technology push approach. The trends highlight how people's behavior is about to change, and how services can support new ways of acting such as hybrid working, sharing economy, sustainable consuming and smart hygiene practices. Many service opportunities can be found when focusing on local user communities and their needs as well as occupants as content providers. The service opportunities that we have identified encourage service providers to focus on occupant experience in the service design. Smart building should support the daily activities of different stakeholders, both regular and occasional occupants, and also link to the occupants' daily lives outside the building. Digital services should be easily available, and the services should be personalized according to the individual needs and preferences of the occupants. Services can guide the occupants in a positive manner towards healthy, safe, and sustainable behavior. Servitization will provide occupants new possibilities to utilize physical spaces and equipment, and smart building services can support this.

(C) Smart building as an always ready, still continuously evolving ecosystem

As pointed out by Alexander [20], built environment is always complete but still always evolving. In a smart building, the constantly evolving set of available services supports a living connection between the building and the occupants. The wide ecosystem of smart building stakeholders and the digital services can speed up the evolution of the built environment. Our approach to engaging the smart building stakeholders in service design has supported creating and maintaining an ecosystem within the multiorganizational project group. The ecosystem has been extended to the various building occupants and other stakeholders. The recognized service opportunities together with more concrete experience goals for occupants can boost the active participation of different actors in value creation in the smart building enabled ecosystems (cf. [42]). As pointed out by Ketonen-Oksi and Valkokari [42], Elia et al. [49], Cennamo and Santalo [50] and Autio et al. [51], physical and digital platforms are crucial tools in the ecosystems to support value co-creation and collaboration. A smart building acts as a physical platform that should be complemented with a digital platform where new services and service providers can be seamlessly integrated into the ecosystem. Smart city research emphasizes citizen involvement and communality (e.g., $[15,25,28,29]$. A similar role should be provided to the occupants of smart buildings. A smart building should engage and empower occupants to participate in developing and providing services and building and maintaining communities accordingly. Our study took place during the COVID-19 pandemic, and we identified new kinds of needs regarding smart hygiene and hybrid work. A smart building should be able to respond quickly to similar kinds of new service needs. The rapid development of 
smart machines will probably show in the smart building service offering, and in the near future service robots will take care of many routine services. For example, multipurpose robots can analyze the cleanliness of surfaces, evaluate air quality and clean (see e.g., [63]). A smart building should provide a flexible environment for service providers where they can easily introduce new services, thus gradually complementing the smart building.

To conclude, our studies have shown that a smart building should be interlinked with the surrounding smart city, it should provide good experiences to the various occupants of the building and the smart building should be evolving by introducing new services that support the evolving needs and practices of the occupants. We want to contribute to the smart building (and smart city) discussions by emphasizing that smart buildings should be developed within the perspective of smart city targets and the role of the built environment in there (cf. [19]). We also suggest that more attention should be paid to the various occupants of the building, and how they experience living, working and vising there. The occupants should not be seen just as "building users" but the building should be studied within a broader context of their lives and local culture. This kind of occupant perspective can support the attempts to make people active agents of change as users of services and technologies supporting systemic change towards sustainability. A building can be made smart with a wide, coherent set of enjoyable services that are continuously evolving in the process of co-creation of different occupants and other stakeholders within the layered service ecosystems of buildings and cities. These services constitute of digital solutions, changes in the built environment as well as human activities. Providing the services will require a common service platform that can bring together an ecosystem of stakeholders and also create links between the different layers. This facilitates a balanced development of the smart building where human and technology perspectives merge; sustainability targets of the cities can progress; and business flourish.

The practical implications of this study include nine service opportunities and concrete user experience goals for four key smart building occupant groups. These results can serve building owners and service providers in developing smart building services. The identified service opportunities were based on studies carried out in Finland although, for example, a majority of the participants were working at global enterprises at the time and thus their viewpoint was at least somewhat international. There may be also other opportunities that were not identified in our study. There may also be cultural differences and other factors that may hinder the identified opportunities in other countries.

Although this paper was strongly rooted in the collaborative study with strong practical aims of the project, this study can provide some avenues for theorizing the role of built environment and future research. Firstly, clearer conceptualization of "smartness" is needed for ensuring accumulating the research knowledge on the smart cities and buildings as well as for progressing in practical development. The attributes we provided are openings for future conceptualizations and studies but only scratch the surface in this area of research. The future research can pursue towards similar characterization as Alexander's 15 fundamental properties of wholeness and make connections between the dimensions of the smartness with them (see [64]). With new smart elements and services we could then bring these properties into modern buildings and turn them more humane. Secondly, bridging different perspectives (cf. [15]) is essential and we would like to encourage studies that (a) link smart buildings and smart cities, (b) bring human, technology and business perspective together as demonstrated here with the design thinking approach and (c) aim to benefit from the insights of various stakeholders ranging from top scientists of different disciplines to champions of the actual development of the built environment. Thirdly, the list of the smart building related trends can also provide a starting point for more focused studies of each of them.

Finally, integrating different perspectives and disciplines into a coherent process of new knowledge creation is always challenging and time consuming. One's passion for one's own topic should not lead to disavowal of other perspectives. Getting over "the battle" between more humane and technology-driven approaches is the key to creating 
the preferred future for us all and to really benefiting from the various efforts. A common mission of sustainability and adoption of a new viewpoint-as we did with the business and service perspective-that requires human and technology viewpoints to be integrated is an efficient path toward progress.

Author Contributions: Overall framing, introduction, and research implications, M.N.; Methods, E.K., J.H., M.N.; Trends, A.M.; UX vision and Goals, E.K., all other sections have been co-authored by M.N., E.K., A.M., J.H. and S.S. All authors have read and agreed to the published version of the manuscript.

Funding: This research was funded by Business Finland (4472/31/2019), VTT Technical Research Centre of Finland Ltd (123815) and the participating companies.

Institutional Review Board Statement: Ethical review and approval were waived for this study due to the fact that the study obeyed the ethical guidelines of VTT Technical Research Centre of Finland Ltd and was conducted under the supervision of VTT's ethical board.

Informed Consent Statement: Informed consent was obtained from all subjects involved in the study.

Data Availability Statement: This research does not include any publicly archived datasets.

Acknowledgments: The authors wish to thank all the project partners and building stakeholders who participated in the different design thinking activities. The authors also wish to thank the co-researchers who participated in planning and carrying out the user studies and workshops as well as literature analytics.

Conflicts of Interest: The authors declare no conflict of interest.

\section{References}

1. Talari, S.; Shafie-Khah, M.; Siano, P.; Loia, V.; Tommasetti, A.; Catalão, J.P. A review of smart cities based on the internet of things concept. Energies 2017, 10, 421. [CrossRef]

2. Jiang, B. A recursive definition of goodness of space for bridging the concepts of space and place for sustainability. Sustainability 2019, 11, 4091. [CrossRef]

3. Xu, H.; Geng, X. People-Centric Service Intelligence for Smart Cities. Smart Cities 2019, 2, 135-152. [CrossRef]

4. Bliss, D.; Garbos, R.; Kane, P.; Kharchenko, V.; Kochanski, T.; Rucinski, A. Homo Digitus: Its Dependable and Resilient Smart Ecosystem. Smart Cities 2021, 4, 514-531. [CrossRef]

5. Moreno, C.; Allam, Z.; Chabaud, D.; Gall, C.; Pratlong, F. Introducing the "15-Minute City": Sustainability, resilience and place identity in future post-pandemic cities. Smart Cities 2021, 4, 93-111. [CrossRef]

6. Romero, M.; Guédria, W.; Panetto, H.; Barafort, B. Towards a characterisation of smart systems: A systematic literature review. Comp. Ind. 2020, 120, 103224. [CrossRef]

7. UN 2021 Sustainability Development Goals: 11 Sustainable Cities and Communities. Available online: https://www.un.org/ sustainabledevelopment/cities/ (accessed on 30 October 2021).

8. European Commission. 100 Climate-Neutral Cities by 2030-By and for the Citizens, Interim Report of the Mission Board for ClimateNeutral and Smart Cities; EC: Brussels, Belgium, 2020.

9. Wu, P.; Xia, B.; Zhao, X. The importance of use and end-of-life phases to the life cycle greenhouse gas (GHG) emissions of concrete-A review. Renew. Sust. Energy Rev. 2014, 37, 360-369. [CrossRef]

10. IEA \& UNEP. Global Status Report 2018: Towards a Zero-Emission, Efficient and Resilient Buildings and Construction Sector; Global Status Report; International Energy Agency, United Nations Environment Programme, 2018; p. 325. Available online: https: / / www.worldgbc.org/sites/default/ files/2018\%20GlobalABC\%20Global\%20Status\%20Report.pdf (accessed on 30 October 2021).

11. Patrão, C.; Moura, P.; de Almeida, A.T. Review of Smart City Assessment Tools. Smart Cities 2020, 3, 1117-1132. [CrossRef]

12. Jiang, B. Living Structure Down to Earth and Up to Heaven: Christopher Alexander. Urban Sci. 2019, 3, 96. [CrossRef]

13. Mehaffy, M.W. Assessing Alexander's Later Contributions to a Science of Cities. Urban Sci. 2019, 3, 59. [CrossRef]

14. Jiang, B.; de Rijke, C. Structural Beauty: A Structure-Based Computational Approach to Quantifying the Beauty of an Image. J. Imaging 2021, 7, 78. [CrossRef] [PubMed]

15. Agbali, M.; Trillo, C.; Ibrahim, I.A.; Arayici, Y.; Fernando, T. Are Smart Innovation Ecosystems Really Seeking to Meet Citizens' Needs? Insights from the Stakeholders' Vision on Smart City Strategy Implementation. Smart Cities 2019, 2, 307-327. [CrossRef]

16. Sullivan, M. Smart Cities: Growing New IT Markets; BCC Research LLC: Massachusetts, MA, USA, 2018; Available online: https: / / corporate.bccresearch.com/market-research/information-technology/smart-cities-growing-new-it-markets-report.html (accessed on 30 October 2021).

17. Statista. Smart City Revenue Worldwide 2020-2025. Available online: https://www.statista.com/statistics/1111626/worldwidesmart-city-market-revenue/ (accessed on 30 October 2021). 
18. Fortune. Revenue of the Building Automation Market Worldwide 2020-2023, Market Research Report. p. 160. Available online: https:/ / www.fortunebusinessinsights.com/industry-reports/smart-building-market-101198 (accessed on 10 December 2021).

19. Apanaviciene, R.; Vanagas, A.; Fokaides, P.A. Smart building integration into a smart city (SBISC): Development of a new evaluation framework. Energies 2020, 13, 2190. [CrossRef]

20. Alexander, C. Sustainability and Morphogenesis: The Birth of a Living World; Schumacher Lecture: Bristol, UK, 2004; Available online: https: / / www.livingneighborhoods.org/library/schumacher-pages-1-28.pdf (accessed on 10 December 2021).

21. Ritala, P.; Almpanopoulou, A. In defense of "eco" in innovation ecosystem. Technovation 2017, 60-61, 39-42. [CrossRef]

22. Polese, F.; Payne, A.; Frow, P.; Sarno, D.; Nenonen, S. Emergence and phase transitions in service ecosystems. J. Bus. Res. 2020, 127, 25-34. [CrossRef]

23. Moore, J.F. Predators and prey: A new ecology of competition. Harv. Bus. Rev. 1993, 71, 75-86.

24. Buckman, A.H.; Mayfield, M.; Beck, S.B. What is a smart building? Smart Sust. Built Environ. 2014, 3, 92-109. [CrossRef]

25. Silva, B.N.; Khan, M.; Han, K. Towards sustainable smart cities: A review of trends, architectures, components, and open challenges in smart cities. Sust. Cities Soc. 2018, 38, 697-713. [CrossRef]

26. Myeong, S.; Kim, Y.; Ahn, M.J. Smart City Strategies-Technology Push or Culture Pull? A Case Study Exploration of Gimpo and Namyangju, South Korea. Smart Cities 2021, 4, 41-53. [CrossRef]

27. Tobey, M.B.; Binder, R.B.; Chang, S.; Yoshida, T.; Yamagata, Y.; Yang, P.P.J. Urban Systems Design: A Conceptual Framework for Planning Smart Communities. Smart Cities 2019, 2, 522-537. [CrossRef]

28. Anttiroiko, A.V.; Valkama, P.; Bailey, S.J. Smart cities in the new service economy: Building platforms for smart services. AI Soc. 2014, 29, 323-334. [CrossRef]

29. Thomas, V.; Wang, D.; Mullagh, L.; Dunn, N. Where's Wally? In search of citizen perspectives on the smart city. Sustainability 2016, 8, 207. [CrossRef]

30. Vischer, J.C. Applying knowledge on building performance: From evidence to intelligence. Intell. Build. Int. 2009, 1, 239-248. [CrossRef]

31. Andreani, S.; Kalchschmidt, M.; Pinto, R.; Sayegh, A. Reframing technologically enhanced urban scenarios: A Design Research model towards human centered smart cities. Technol. Forecast. Soc. Change 2019, 142, 15-25. Available online: https://www. sciencedirect.com/science/article/pii/s0040162518300052 (accessed on 30 October 2021). [CrossRef]

32. Mugge, R. Product Attachment. Ph.D. Thesis, Faculty of Industrial Design Engineering, Department of Product Innovation and Management, Delft University of Technology, Delft, The Netherlands , 2007. Available online: http://resolver.tudelft.nl/uuid: 0a7cef79-cb04-4344-abb1-cff24e3c3a78 (accessed on 23 April 2020).

33. Dey, M.; Rana, S.P.; Dudley, S. A Case Study Based Approach for Remote Fault Detection Using Multi-Level Machine Learning in A Smart Building. Smart Cities 2020, 3, 401-419. [CrossRef]

34. Shove, E. Users, technologies and expectations of comfort, cleanliness and convenience. Innov. Eur. J. Soc. Sci. Res. 2003, 16, 193-206. [CrossRef]

35. Kaasinen, E.; Kymäläinen, T.; Niemelä, M.; Olsson, T.; Kanerva, M.; Ikonen, V. A user-centric view of intelligent environments: User expectations, user experience and user role in building intelligent environments. Computers 2013, 2, 1-33. [CrossRef]

36. Watson, K.J.; Evans, J.; Karvonen, A.; Whitley, T. Capturing the social value of buildings: The promise of Social Return on Investment (SROI). Build. Environ. 2016, 103, 289-301. [CrossRef]

37. $\mathrm{Xu}, \mathrm{W}$. Enhanced ergonomics approaches for product design: A user experience ecosystem perspective and case studies. Ergonomics 2014, 57, 34-51. [CrossRef]

38. Koskela-Huotari, K.; Edvardsson, B.; Jonas, J.M.; Sörhammar, D.; Witell, L. Innovation in service ecosystems—Breaking, making, and maintaining institutionalized rules of resource integration. J. Bus. Res. 2016, 69, 2964-2971. [CrossRef]

39. Siltaloppi, J.; Koskela-Huotari, K.; Vargo, S.L. Institutional complexity as a driver for innovation in service ecosystems. Serv. Sci. 2016, 8, 333-343. [CrossRef]

40. Aarikka-Stenroos, L.; Ritala, P. Network management in the era of ecosystems: Systematic review and management framework. Ind. Market. Manag. 2016, 67, 23-36. [CrossRef]

41. Valkokari, K. Business, Innovation, and Knowledge Ecosystems: How They Differ and How to Survive and Thrive within Them. Technol. Innov. Manag. Rev. 2015, 5, 17-24. [CrossRef]

42. Ketonen-Oksi, S.; Valkokari, K. Innovation ecosystems as structures for value co-creation. Technol. Innov. Manag. Rev. 2013, 9, 25-35. [CrossRef]

43. Vargo, S.L.; Akaka, M.A.; Vaughan, C.M. Conceptualizing value: A service-ecosystem view. J. Creat. Value 2017, 3, 117-124. [CrossRef]

44. Vargo, S.L.; Lusch, R.F. Institutions and axioms: An extension and update of service-dominant logic. J. Acad. Market. Sci. 2016, 44, 5-23. [CrossRef]

45. Vargo, S.L.; Wieland, H.; Akaka, M.A. Innovation through institutionalization: A service ecosystems perspective. Ind. Market. Manag. 2015, 44, 63-72. [CrossRef]

46. Akaka, M.A.; Koskela-Huotari, K.; Vargo, S.L. Further advancing service science with Service-Dominant logic: Service ecosystems, institutions, and their implications for innovation. In Handbook of Service Science, Volume II; Springer: Berlin/Heidelberg, Germany, 2019; pp. 641-659. 
47. Lusch, R.F.; Vargo, S.L.; Gustafsson, A. Fostering a trans-disciplinary perspectives of service ecosystems. J. Bus. Res. 2016, 69, 2957-2963. [CrossRef]

48. Gölgeci, I.; Ali, I.; Ritala, P.; Arslan, A. A bibliometric review of service ecosystems research: Current status and future directions J. Bus. Ind. Market. 2021. ahead-of-print. [CrossRef]

49. Elia, G.; Margherita, A.; Passiante, G. Digital entrepreneurship ecosystem: How digital technologies and collective intelligence are reshaping the entrepreneurial process. Technol. Forecast Soc. Change 2020, 150, 119791. [CrossRef]

50. Cennamo, C.; Santaló, J. Generativity tension and value creation in platform ecosystems. Org. Sci. 2019, 30, 617-641. [CrossRef]

51. Autio, E.; Nambisan, S.; Thomas, L.D.W.; Wright, M. Digital affordances, spatial affordances, and the genesis of entrepreneurial ecosystems. Strateg. Entrep. J. 2018, 12, 72-95. [CrossRef]

52. Cennamo, C. Building the Value of Next-Generation Platforms: The Paradox of Diminishing Returns. J. Manag. 2018, 44, 3038-3069. [CrossRef]

53. Nuutinen, M.; Lappalainen, I.; Halttunen, M.; Turtiainen, R.; Kaasinen, E.; Hyvärinen, J. Tensions as drivers for co-innovating towards new digital business ecosystem. In Proceedings of the 21st International CINet Conference: Practising Continuous Innovation in Digital Ecosystems, Politecnico di Milano, 20-22 September 2020; Available online: https: / / www.continuousinnovation.net/events/conferences/2020.html (accessed on 30 October 2021).

54. Toivo, L.; Vähämäki, M. Tilallisuus työssä ja sen muutoksessa: Kotihoidon työn ja organisaatioyhdistymisen tarkastelu fyysisinä, sosiaalisina ja mentaalisina tiloina. (Spatiality in work and in its change). Alue ja Ympäristö 2010, 39, 27-38. (In Finnish)

55. Waheed, Z.; Ogunlana, S.O. Harnessing knowledge of building end-users: Identifying knowledge brokers that matter. J. Corp. Real Estate 2019, 21, 19-35. [CrossRef]

56. Sonta, A.J.; Simmons, P.E.; Jain, R.K. Understanding building occupant activities at scale: An integrated knowledge-based and data-driven approach. Adv. Eng. Inform. 2018, 37, 1-13. [CrossRef]

57. Brown, T. Design thinking. Harv. Bus. Rev. 2008, 86, 84. [PubMed]

58. Lockwood, T. (Ed.) Design Thinking. Integrating Innovation, Customer Experience and Brand Value; Allworth Press: New York, NY, USA, 2009; p. xi.

59. Mattelmäki, T. Design Probes; University of Art and Design: Helsinki, Finland, 2006.

60. Kaasinen, E.; Roto, V.; Hakulinen, J.; Heimonen, T.; Jokinen, J.P.P.; Karvonen, H.; Keskinen, T.; Koskinen, H.; Lu, Y.; Saariluoma, P.; et al. Defining user experience goals to guide the design of industrial systems. Behav. Inf. Technol. 2015, 34, 976-991. [CrossRef]

61. Cuhls, K.E. Mental time travel in foresight processes-Cases and applications. Futures 2017, 86, 118-135. [CrossRef]

62. Kaasinen, E.; Aromaa, S.; Halttunen, M.; Jacobson, S.; Lappalainen, I.; Liinasuo, M.; Nuutinen, M.; Turtiainen, R. User Experience Goals for Cognitive Systems in Smart Business Buildings. In Intelligent Human Systems Integration IHSI 2021; 23 Feb, 2021; Russo, D., Ahram, T., Karwowski, W., Di Bucchianico, G., Taiar, R., Eds.; Springer: Cham, Switzerland, 2021; pp. 440-446.

63. MURO-Let's Build the Future of Service Robotics-Together. Available online: https:/ / www.murorobotics.fi/ (accessed on 31 October 2021).

64. Dickinson, D. Christopher Alexander and the Inadequacy of Genius in the Architecture of the Coming Age. Urban Sci. 2020, 4, 17. [CrossRef] 